Portland State University

PDXScholar

1984

\title{
Normative data for the Tennessee test of rhythm and intonation patterns (T-TRIP)
}

Ray Drommond

Portland State University

Follow this and additional works at: https://pdxscholar.library.pdx.edu/open_access_etds

Part of the Phonetics and Phonology Commons, and the Speech Pathology and Audiology Commons Let us know how access to this document benefits you.

\section{Recommended Citation}

Drommond, Ray, "Normative data for the Tennessee test of rhythm and intonation patterns (T-TRIP)" (1984). Dissertations and Theses. Paper 3297.

https://doi.org/10.15760/etd.3288

This Thesis is brought to you for free and open access. It has been accepted for inclusion in Dissertations and Theses by an authorized administrator of PDXScholar. Please contact us if we can make this document more accessible: pdxscholar@pdx.edu. 
AN ABSTRACT OF THE THESIS OF Ray Drommond for the Master of Science in Speech Communication, with an emphasis in SpeechLanguage Pathology, presented May 30, 1984.

Title: Normative Data for the Tennessee Test of Rhythm and Intonation Patterns (T-TRIP).

APPROVED BY MEMBERS OF THE THESIS COMMITTEE:

Joan McMahon

Chairperson

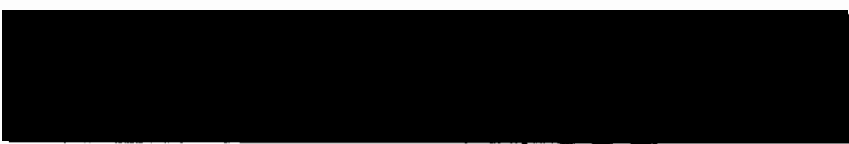

Shari Kazdoy
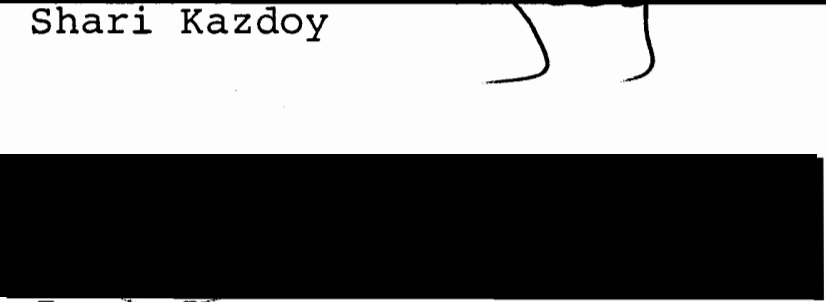

Jomar LoCOCO

Prosody is the flow of speech created by controlling elements such as pitch, rate, loudness, and stress (Tiffany and Carrell, 1977). Prosody is vital to intelligibility of speech and also communicates meaning. Despite the importance of prosody, however, few tests for the adequacy of 
prosodic ability in young children have been published (Koike and Asp, 1981a). To remedy this paucity of tools, Koike and Asp published the Tennessee Test of Rhythm and Intonation Patterns (T-TRIP). The clinical usefulness of the T-TRIP has been limited by a lack of normative data against which to compare individual children's performance.

The purpose of this study was to collect normative data on the T-TRIP scores of normal four and six-year-olds. The question this study asked was: What are the means and standard deviations of T-TRIP scores from the samples of four and six-year-olds? A secondary question was: Are differences between the means of the two age groups statistically significant?

Twenty-four four-year-olds and twenty-five six-yearolds were selected as subjects on the basis of age, and normalcy of speech, language and hearing development. Each subject passed a hearing screening on the day he took the T-TRIP. The mean score for four-year-olds was 20.58 (82 percent) with a standard deviation of 2.45 while the six-year-old mean was 23.32 (93 percent) with a standard deviation of 1.89. A two-tailed t-test revealed the six-year-old mean was significantly greater than the four-year-old mean $(\underline{t}=4.38 ; d f=47$; $\mathrm{p}<0.05)$.

This study generated information about which T-TRIP items were mastered by which age groups. These data may be useful indicators of the deviance or normalcy of performance in various prosodic skills. Inconsistencies in the data, 
however, suggest they should be interpreted and applied with due caution in a clinical setting. 


\section{NORMATIVE DATA FOR THE TENNESSEE \\ TEST OF RHYTHM AND INTONATION \\ PATTERNS \\ (T-TRIP)}

by

RAY DROMMOND

A thesis submitted in partial fulfillment of the requirements for the degree of

MASTER OF SCIENCE IN SPEECH COMMUNICATION:

with an emphasis in

SPEECH-LANGUAGE PATHOLOGY/AUDIOLOGY

Portland State University 
TO THE OFFICE OF GRADUATE STUDIES AND RESEARCH:

The members of the Committee approve the thesis of Ray Drommond presented May 30, 1984.

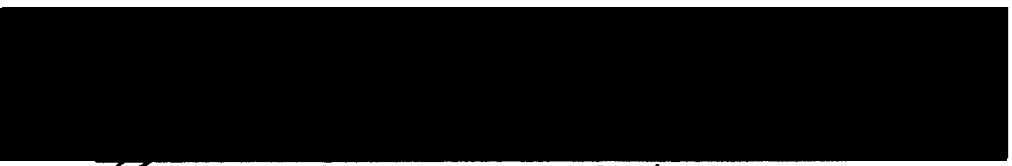

Joan McMahon

Chairperson
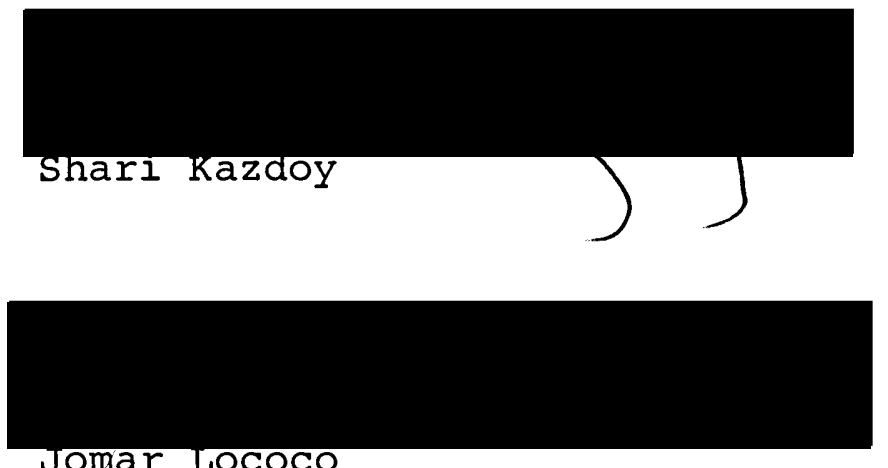

APPROVED :

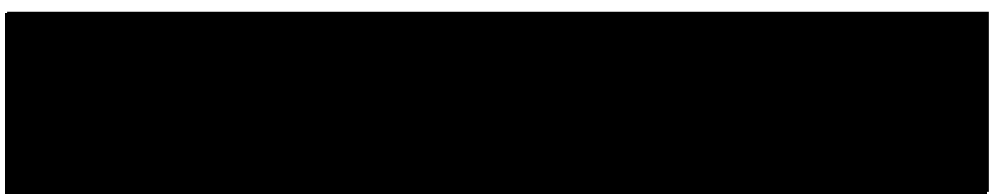

Theodore G. Grove, Chair, Department

of Speech Communication

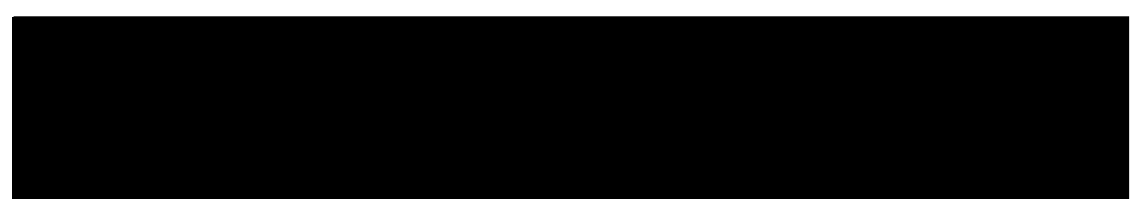

Stanley E. Raugh, Dean, Graduate UW Studies And Research 


\section{ACKNOWLEDGEMENTS}

I am grateful to the following people for the help they gave me in this project:

- Chris, my wife, who's unfailing love and support make each day a joy

- Joan McMahon, my advisor and thesis director, who's good humor and good advice made this project, and my education as a whole, very pleasurable

- Shari Kazdoy who performed "double duty" by helping me through this project and hearing clinic during the same term

- Jomar Lococo who gave fine insights into the mechanics and content of this thesis

- Robert Casteel who freely helped me at every stage of my education, including this project

- Robert English who has provided inspiration throughout my educational career

- Mary Therese Withers who served as a judge in the pilot study

- Gordon Solie who brought a fresh prospective and enthusiasm to the oral examination

- Marilyn Caum who typed the final draft with great care and expertise

- Amelia Drommond, my mother, who got me started on the right track in so many ways. 
TABLE OF CONTENTS

Page

ACKNOWLEDGEMENTS

iii

LIST OF TABLES

LIST OF FIGURES

vi

CHAPTER

I INTRODUCTION AND STATEMENT OF PURPOSE

Introduction

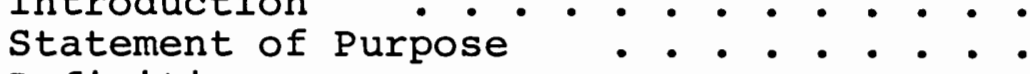

Definitions

II REVIEW OF THE LITERATURE

Summary of the Review . . . . . . .

5

13

III METHODS AND PROCEDURES

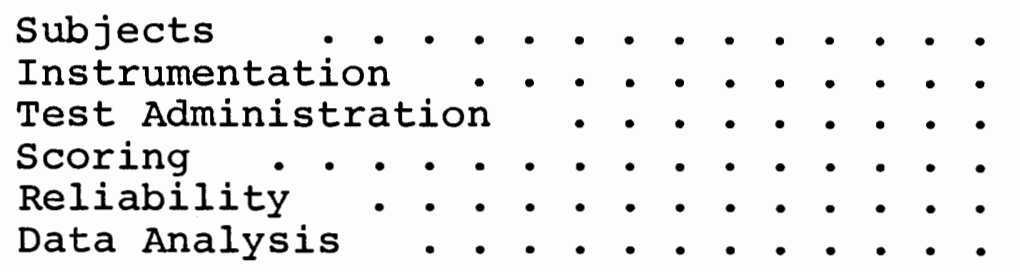

IV RESULTS AND DISCUSSION

Results .. . . . . . . . . .

Discussion ...............

$\mathrm{V}$ SUMMARY AND IMPLICATIONS

Summary

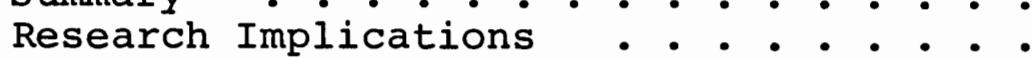

Clinical Implications . . . . . . 36

BIBLIOGRAPHY 


\section{LIST OF TABLES}

TABLE

Page

I Summary of Unpublished Studies Using the T-TRIP . . . . . . . . . . . .

II Characteristics of Sample . . . . . . . 15

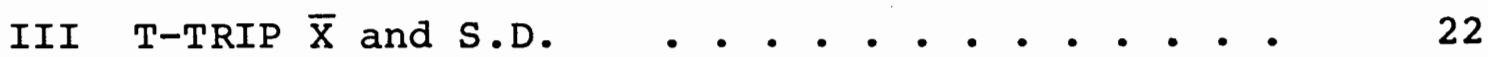

IV T-TRIP Items Missed BY 4 Year-Old Boys . . . 23

V T-TRIP Items Missed By 4 Year-Old Girls • • 24

VI T-TRIP Items Missed By 6 Year-old Boys • • • 25

VII T-TRIP Items Missed BY 6 Year-old Girls . • 26 


\section{LIST OF FIGURES}

FIGURE

Page

1. Statistical significance of differences

2. Four and six-year-old T-TRIP scores obtained in this study compared with three and five-year-old T-TRIP scores obtained by Koike and Asp (1981a).

3. The percentage of children who were scored as correct on individual T-TRIP Items 
CHAPTER I

INTRODUCTION AND STATEMENT OF PURPOSE

Introduction

The basic building blocks of spoken language are the speech sounds called segmental phonemes. One way we express meaning is by forming words from the segmental phonemes (Perkins, 1977). Meaning is also conveyed by suprasegmental features sometimes called prosody or prosodic elements (Faircloth and Faircloth, 1973). Various authors have included different combinations of the following elements under the rubric of prosody: pitch, stress, intonation, loudness, intensity, duration, rhythm, juncture, tempo, voice quality, pause, tension, and prominence (Netsell, 1973; Wood, 1981; Crystal and Quirk, 1964). Prosody has been called the "melody of our language" (Wood) and was summarized by Tiffany and Carrell (1977) as a flow of acoustic energy on which segmentals are carried. The flow is characterized by dynamic changes of power, pitch, and vocal quality with rate and the use of pauses also part of the melody of speech.

Prosodic elements contribute to speech in a variety of ways and according to Abe (1980) help differentiate phonologically similar words such as pré.sent ("Here is a Christmas present.") and pre.sent' ("Present your argument."). Prosody 
also gives affective content to speech. The words "come here," for example, have one meaning when spoken with the stentorian prosody of an angry parent talking to a disobedient child. "Come here," if spoken with the low pitch and slow tempo of one newlywed to another, communicates a very different message. Lieberman (1977) wrote that prosody serves a function in speech similar to that served by punctuation in writing. Appropriate use of pause, pitch, and loudness, for example, signals the end of sentences. This is vital information in the turn-taking which characterizes conversation. Shifts in prosody can also differentiate questions ("Oh?") from statements ("Oh.") or exclamations ("Oh!") (Tiffany and Carrel1, 1977). Perhaps the most important function of prosody is to give cues for understanding concatonated speech. The words in a sentence, rather than being as distinct as beads on a string, are "smeared" together with some sounds omitted and others changed by the effect of surrounding sounds (Nakatani and Schaffer, 1978). Prosodic elements give powerful cues for identifying the intended words (Martin, 1979). This function of prosody, taken for granted in normal speech, becomes evident when faulty in the speech of some unintelligible children (Koike and Asp, 1981a). Such speakers may form segmental phonemes correctly yet subvert their intelligibility by incorrect use of prosody.

Despite its central role in speech, however, prosody has received little attention from theoreticians (Crystal, 1969) or clinicians (Shadden, Asp, Tonkovich, and Mason, 
1980). Few tools are available to help clinicians assess prosodic strengths and weaknesses in unintelligible speakers. To remedy this lack, Koike and Asp (198la) published the Tennessee Test of Rhythm and Intonation Patterns (T-TRIP). The T-TRIP measures children's ability to imitate patterns of stress, rhythm, intonation and pause. Initial studies described by Koike and Asp showed the T-TRIP is sensitive to age differences. Studies involving normal children between three and nine years of age showed older children scored higher than younger children. However, no methodical collection of normative data has been reported. According to Weiss, Lillywhite, and Gordon (1980) normative data provide landmarks for judging if speech elements are delayed or disordered and can give clues about when and where to start intervention. T-TRIP norms would help clinicians determine which of their unintelligible clients have abnormally poor use of prosody and also help in selecting specific targets for clinical intervention.

Koike (1983) reported that an appropriate group from which to gather normative data is under seven years of age because children's T-TRIP scores plateau at that age. Normative data for children in these younger age groups would yield norms which should make the T-TRIP a useful tool for school speech and hearing clinicians. 
Statement of Purpose

The purpose of this study was to obtain normative data on T-TRIP scores of four and six-year-old children with normal speech and language.

This study sought to answer the following question:

What are the means and standard deviations of T-TRIP scores from the samples of normal four and six-year-olds? A secondary question was: Are differences between the means of the age groups statistically significant?

\section{Definitions}

Intonation: Intonation is a measure of how quickly, and by how many tones, a person changes pitch while speaking. Intonation is therefore pitch changing as a function of time (Koike and Asp, 198la).

Rhythm: Rhythm is a pattern of adjacent syllables having a characteristic combination of pitch, loudness, and duration (Crystal, 1975).

Stress: Stress is variation of pitch, loudness, and duration. A stressed syllable is generally longer, louder and higher pitched than adjacent syllables (Daniloff, Schuckers and Feth, 1980).

Tempo: Tempo is the rapidity with which syllables are spoken (Koike and Asp, 1981a). 
CHAPTER II

REVIEW OF THE LITERATURE

According to Wood (1981), infants understand and use prosody earlier than any other dimension of speech. Long before they can understand the symbolic meaning of words, babies use shifts in pitch, pause, loudness, and tempo to communicate basic needs. Babies, for example, often have a characteristic cry which signals hunger. Wood described this cry as loud, medium pitched, and having a regular rhythm. Pain cries, in contrast, are long, high pitched squeals. Cries of fatigue are identified by their low pitch, variable loudness, slow pace, and the presence of grunts or sucking noises. It has been hypothesized that these early, differentiated cries are important precursors to babbling and basic sentence forms (Lieberman, 1967).

Not only do babies express meaning through use of prosody, they attend to prosody in adult speech. Long before they can understand propositional speech, babies can react to "whole tonal patterns" (Lenneberg, 1967). Menyuk (1972), for example, reported that by four to eight months of age babies have different physical reactions (heart rate and motor behavior) to questions and statements. Even when a single set of words was stated as a question then as a statement, the different reactions persisted. Other authors (e.g., Lewis, 
1959; Crystal, 1973) have corroborated that babies are sensitive to prosodic patterns quite early in life.

As children grow they gradually become more dependent on words to express their meaning (Lenneberg, 1967). The prosodic elements of speech, nonetheless, remain the substrate upon which segmental phonemes are carried (Tiffany and Carrell, 1977). The sequence in which children integrate prosodic elements into their speech, however, has not been determined (Crystal, 1975; Ling, 1976; Shadden, Asp, Tonkovich, and Mason, 1980). Research into the acquisition of prosodic abilities in children's speech has been hampered by a lack of appropriate measurement tools (Crystal, 1975; Koike and Asp, 1981a). This is not to say that no tools have emerged. The tests of prosody which have been published, however, have been cursory and/or unsuitable for use with young children. Ling (1976), for example, included a brief test for pitch, duration and intensity in his Phonetic Level speech Evaluation for the hearing impaired. While the test is suitable for children, it provides relatively gross measures of the subject's ability to vary each of the parameters in isolation. Coe (1978), as part of a screening instrument, required subjects to listen to a speaker then choose the corresponding sentence from a printed list (e.g., "He lives in the White House" or "He lives in the white house"). Coe's evaluation technique gives some information about a subject's discrimination of prosody but is inappropriate for young children because it requires the subject to read. The need for 
reading also limits use of the Minimal Auditory Capabilities (MAC) battery (Owens, Kessler, and Schubert, 1982). Two subtests of the MAC battery required subjects to distinguish stress patterns and pitch changes in speech samples, then point to appropriate items on a printed list. While the MAC battery is useful in screening severely hearing-impaired candidates for cochlear implants, it is not useful for young children because of the reading component (Reese, 1983). Pinheiro (1976) developed the Pitch Pattern Test in which subjects imitated patterns of three tones, with each tone being either high or low (e.g., high-low-high, low-low-high, etc.). Pinheiro's test, which was designed to detect central auditory problems, appears to hold promise as a measure of pitch discrimination and expression but this is only one parameter of prosody.

The Seashore Measures of Musical Talent (Measures), published in 1919 by C.E. Seashore, was not designed as a speech test (Lehman, 1968). The Measures, however, was a comprehensive analysis of the skills which comprise prosody, including subtests for discrimination of pitch, rhythm, loudness, and duration. Each subtest required subjects to make a same/different determination about pairs of recorded test items. In the pitch subtest, for example, the subject had to judge if the second of two tones was lower or higher than the first. The fifty pairs of oscillator-produced tones included pairs differing by seventeen, twelve, eight, five, four, three, and two Hertz (Hz.) The other subtests followed a 
similar format. Travis and Davis (1927) recognized the connection between "certain musical talents" and smooth speech. Although Travis and Davis used non-specific criteria, they found people judged as poor speakers scored lower on the Measures than did good speakers. The authors attributed the lower scores to a variety of reasons including poorer auditory monitoring of speech. A search of the literature revealed little use of the Measures in assessment of speech problems, probably because they have definite limitations as speech tests. The Measures emphasized low frequencies (180 $\mathrm{Hz}$. to $500 \mathrm{Hz.}$ ) and yielded no information about important speech frequencies between $500 \mathrm{~Hz}$, and $6,000 \mathrm{~Hz}$. The measures tested receptive skills and therefore gave no information about expressive ability. The Measures used oscilatorproduced tones so the results may not accurately reflect receptive speech skills.

While the Measures had limitations, elements were included which are appropriate to the investigation of prosody. The Measures targeted pitch, duration, loudness, and rhythm which are central to prosody. The Measures used recorded test items which allowed consistent test presentation and did not require subjects to read. Finally, the Measures used nonpropositional stimulus items which allowed subjects to attend to the target features without being distracted by the meaning of words.

Oller (1973) also employed nonpropositional stimuli to study prosodic expression. Oller used the nonsense syllable 
"ba" to study the tendency of the final syllable in an utterance to be longer in duration. Subjects repeated the syllable in rhythm with other words, for example, "ba.ba.ba'.ba" had the same rhythm as "concentration." When analyzed by a Sonograph the "b" showed as a sharp spike which made measurement of duration precise. The results of the study are of some interest because they verified the importance of duration in intelligibility. More germane to the present study, however, is oller's methodology. He demonstrated that when subjects say nonsense syllables, the prosodic features can be studied more precisely. The uniform phonological setting provided by nonsense syllables highlights prosodic elements more vividly than would propositional speech.

Lieberman and Streeter (1978) showed that imitation of speech patterns using nonsense syllables gives an accurate picture of how people use prosodic features in propositional speech. They recorded two subjects saying ten declarative sentences. The subjects then imitated the sentences, substituting "ma" for each syllable while retaining the rhythm and intonation of the target. Results showed the nonsense syllable imitations had prosodic patterns nearly indistinguishable from the target sentences. An implication of the Lieberman and streeter study is that imitations of prosodic patterns using nonsense syllables can accurately reflect prosody in propositional speech.

The T-TRIP, origninally devised as part of a masters thesis (cited in Koike and Asp, 1981a), was published to 
provide a tool for quantifying prosodic ability. Like the Measures discussed above, the T-TRIP requires subjects to discriminate variations in pitch, duration, loudness, and rhythm. The T-TRIP, however, also requires subjects to use those elements.

The T-TRIP has been employed in two published studies (Shadden, et. al., 1980; Koike and Asp, 1981a) and five unpublished studies, a summary of which is shown in Table I. According to Koike (1983) the unpublished studies are not readily available and are adequately described in his article (Koike and Asp, 1981a). As can be seen in Table 1, most of the unpublished studies involved adult or impaired subjects. Those studies which involved normal children used low numbers of subjects. Koike therefore characterized the present study as a necessary step in making the T-TRIP a useful tool for testing children.

The first published study employing the T-TRIP was conducted by Shadden, et al., (1980). They tested a total of twenty children and found five-year-olds with inadequate articulation scored lower $(\bar{x}=69 \%)$ on the T-TRIP than did children of the same age with adequate articulation $(\bar{x}=79 \%)$. The difference between the two groups was not statistically significant but the authors hypothesized that uncontrolled variables (e.g., previous speech intervention) may have misleadingly elevated the scores of the inadequate articulation group. Shadden and her co-authors commented that the interaction of articulation and prosody needs further investigation 


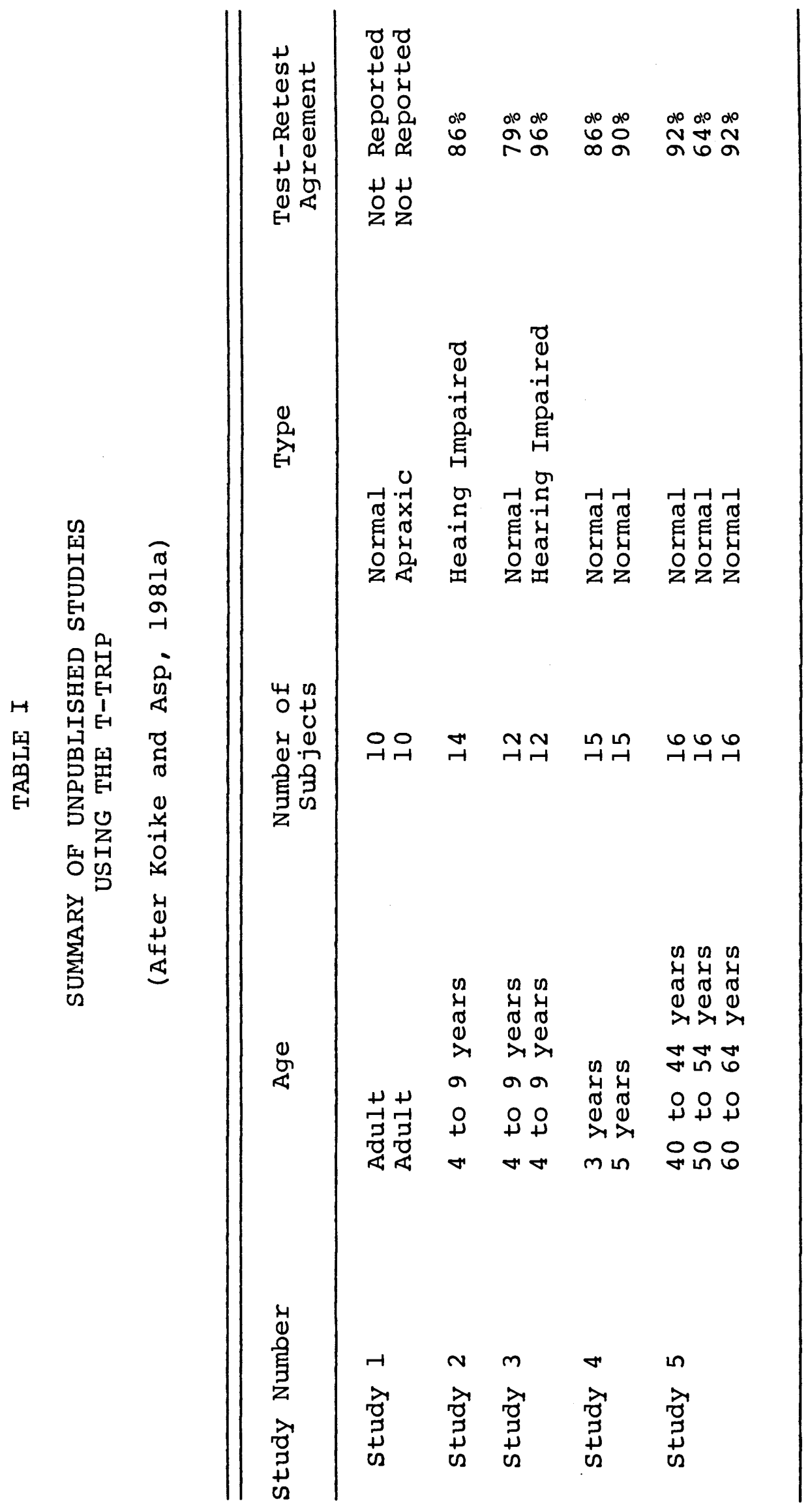


as does the acquisition of prosodic abilities.

Koike and Asp (1981a) tested ten normal children from the three and five-year-old age groups. Results showed the younger group scoring significantly lower $(\bar{x}=60 \%)$ than the older group $(\bar{x}=86 \%)$. Specific aspects of the test were harder for the three-year-olds, for example the degree of difficulty apparently increased when the tempo quickened or the number of syllables increased. All the children had difficulty imitating a pause. Rising and falling intonations were not especially difficult except when both were combined in the same test item. The hardest intonation pattern, especially for the three-year-olds, was falling to rising (e.g., test item 20).

Koike and Asp's (1981a) study, at best, provided preliminary insights into an acquisition hierarchy of prosodic features and at least gave information about the prosodic repertoire of three and five-year-olds.

Two main factors must be considered in judging a test instrument: reliability and validity. The former was addressed by Koike and Asp (1981a) when they performed a testretest procedure on two of their subjects. Agreement within a panel of three judges was 84 percent on test-retest of a three-year-old and 92 percent for a five-year-old. Similar results were reported for several unpublished studies (see Table I). The T-TRIP therefore appears to be reliable, i.e., similar results came from multiple administration to the same subject. 
The validity of the T-TRIP, in a strict sense, is quite good. The authors claimed it measures imitative ability and it apparently does so. It is tempting to assume that when children correctly imitate a prosodic element that the element is part of their everyday speech repertoire. Such an assumption, however, is not supported by the literature (shadden, et. al., 1980). The relationship between imitation of a feature and its use in spontaneous speech is not yet known.

\section{Summary of the Review}

Prosody is a group of speech elements which add meaning to our utterances in a variety of ways. While it is known that babies acquire prosodic abilities at a very young age, specific information about the order and chronology of acquisition is lacking. Also lacking are test instruments suitable for investigating prosody in the pre-literate population. The T-TRIP is an instrument suitable for use with young children but no norms have been established. T-TRIP users, therefore, have meager data against which to compare a child's score. Norms are needed to make the T-TRIP a useful clinical tool. 


\section{CHAPTER III}

\section{METHODS AND PROCEDURES}

\section{Subjects}

The forty-nine subjects of the study were twenty-four four-year-olds (4-0 through 4-11) and twenty-five six-yearolds (6-0 through 6-11). The mean ages for subjects were 4-8 for four-year-olds and 6-7 for six-year-olds. All subjects were classified as "normal" by a Speech-Language Pathologist holding a current Certificate of Clinical Competence (CCC) from the American Speech-Language-Hearing Association (ASHA). To be considered normal, subjects demonstrated speech, language, and hearing skills comensurate with their age and had not undergone speech-language intervention. In addition, each subject passed a hearing screening on the day of testing. The study originally included twenty-five subjects from each age group but one four-year-old who passed all other criteria gave numerous perseverative responses and therefore was excluded. The exclusion of this subject explains the unequal number of subjects in the two age groups. The subjects were chosen from three elementary schools in the Portland area without regard for sex, ethnic background or socio-economic status (SES). Table II shows the composition of the sample, broken down by these characteristics. 
TABLE II

CHARACTERISTICS OF SAMPLE

\begin{tabular}{ccccccccc}
\hline Group & Boys $\frac{\text { Sex }}{\text { Girls }}$ & White $\frac{\text { Ethnic }}{\text { Black }}$ & $\frac{\text { Family Income (in } \$ 1000) *}{12}$ \\
\hline $\begin{array}{c}4 \\
\text { year-old }\end{array}$ & 12 & 12 & 16 & 8 & 7 & 5 & 9 & 3 \\
$\begin{array}{c}6 \\
\text { year-old }\end{array}$ & 11 & 14 & 20 & 5 & 7 & 7 & 9 & 2 \\
\hline
\end{tabular}

* The estimate of family income is an indicator of SES based on information provided by school personnel knowledgable about the students' family cirucmstances.

\section{Instrumentation}

The Tennessee Test of Rhythm and Intonation Patterns (T-TRIP) (Koike and Asp, 1981a) is a three-part prosody test in which the subject listens to stimulus items then imitates them as accurately as he can. The test manual (Appendix A) (Koike and Asp, 1981b) specifies that each of the twenty-five test items be presented twice with the subject imitating each repetition. The T-TRIP consists of the following parts:

1. Rhythm -- 14 items testing stress and tempo.

2. Rhythm -- 3 items testing tempo.

3. Intonation -- 8 items testing pitch and tempo.

Each test item consists of the nonsense syllable /ma/ spoken with specific rhythm and intonation patterns. The T-TRIP, as used in this study, was recorded on an audio tape cassette by Koike, co-author of the instrument. The T-TRIP 
test form (Appendix B) shows the symbols and notation used to graphically represent test items. Each syllable is shown as a single dot on a three-line musical staff.

Part I of the rhythm section contains systematically varied combinations of tempo, stress, and pause. The items in Part I are progressively longer and more difficult. In Part II the tempo and number of syllables per beat increase with successive items. For Part III each item has a different intonation pattern while rhythm changes every other item. Part III, therefore, is a set of four pairs of items, each pair sharing the same rhythm but having different intonation.

A bilateral, air conducted, pure tone hearing screening was administered at twenty-five decibels for the frequencies of $500,1000,2000,3000,4000$, and 6000 Hertz. Either a Beltone Model $10 \mathrm{D}$ or a Maico Model MA-2B portable audiometer calibrated per ANSI 1969 specifications was utilized.

For presenting and recording the test sessions, either a Gold Star Model TCM-508 or a Bell and Howell Mode 3179A tape recorder fit with a Gold Star Model DM-1000 microphone was used.

\section{Test Administration}

Each school provided a quiet test area isolated from other people. Test areas contained two chairs plus a table on which an audiometer and two cassette tape recorders were placed. While one recorder was used to present test items, the other recorder was fit with a remote microphone and was 
used to record the subject's responses. The subject was seated across the table, facing the tester during test sessions.

Testing was conducted during school hours and subjects were individually brought to the test area from their class. The examiner and subject established rapport by conversing for about five minutes before starting the audiometric screening. Audiometric screening employed a portable earphoneequipped audiometer through which air conducted pure tones were presented bilaterally. Subjects were instructed to raise their hands when they heard the tones. Only those subjects who responded to $500,1000,2000,3000,4000$, and 6000 Hertz (at 25 dBHL) were given the T-TRIP.

Prior to administering the T-TRIP the tester played a test tone (at the start of the test tape) to establish a comfortable listening level for the subject. Introductory instructions were then read to the subject by the examiner as specified in the test manual. The instructions prepared the subject for the imitative tasks which followed.

The first five test items were practice items which gave the subject further opportunity to become familar with the test format. Each practice item was presented only once. The practice items were repeated if the subject misunderstood the task or gave consistently incorrect responses. The stimulus tape was stopped between items to allow enough time for the subject to respond. The process of stopping the tape between test items continued throughout the test. 


\section{$\underline{\text { Scoring }}$}

The tester scored each response on the test form (Appendix B) as correct $(+)$ or incorrect $(-)$. To be scored correct, the subject was required to use the appropriate stress, pause, tempo, and number of syllables. The intelligibility of the syllables was not considered in judging the correctness of responses. A test item was scored correct if either of the two repetitions was correct. The subject's T-TRIP score was figured from the number of correct responses out of a total of twenty-five. This score was expressed as a percentage correct.

\section{$\underline{\text { Reliability }}$}

Six subjects ranging in age from five-years-old to adult, participated in a pilot study. The researcher administered the T-TRIP to the subjects, recording their responses on audio cassette. These six test-session tapes were then independently scored by a Speech-Language Pathologist holding ASHA CCC-SP using criteria specified in the test manual (Appendix A). Reviewing the six sessions, the researcher and the judge agreed on 147 of the total 150 test items; therefore, inter-judge reliability was established at .98 .

To determine intra-judge reliability, the examiner rescored two taped test sessions one week after the initial administration. Intra-judge reliability was 100 percent. 


\section{Data Analysis}

The researcher administered, recorded responses, and scored all tests. To find the average score for each age group, the arithmetic mean was computed. To determine the dispersion of each group's scores, the standard deviation and range were computed. To determine the significance of differences between the scores of the two age groups, the $t$-test was employed. 
CHAPTER IV

RESULTS AND DISCUSSION

$\underline{\text { Results }}$

The purpose of this study was to gather normative data on Tennessee Test of Rhythms and Intonation Pattern Test ( $\mathrm{T}$ TRIP) scores of normal four and six-year-olds. The question asked by the study was: What are the means $(\bar{x})$ and standard deviations (S.D.) of T-TRIP scores from the sample of four and six-year-olds? A secondary question was: Are differences between the means of the two groups statistically significant?

To determine means, standard deviations, and statistical significance, these data were analyzed and the results are in Figure 1 and Table III. Tables IV, V, VI, and VII, show correct and incorrect items for each subject by age level. The four-year-old mean score of 20.58 ( $\mathrm{SD}=2.45)$ was significantly lower than the six-year-old mean of 23.32 (SD=1.89) when a two-tailed $\underline{t}$-test was used ( $t=4.38 ; d f=47 ; p<.005)$. The data within each age group were analyzed using a two-tailed t-test to determine if boys and girls scored differently. The four-year-old girls mean of 21.8 was significantly higher than the four-year-old boys mean of 19.4 ( $t=2.69 ; d f=22 ; p<.05)$. Among six-year-olds, however, the opposite was true, that is, 


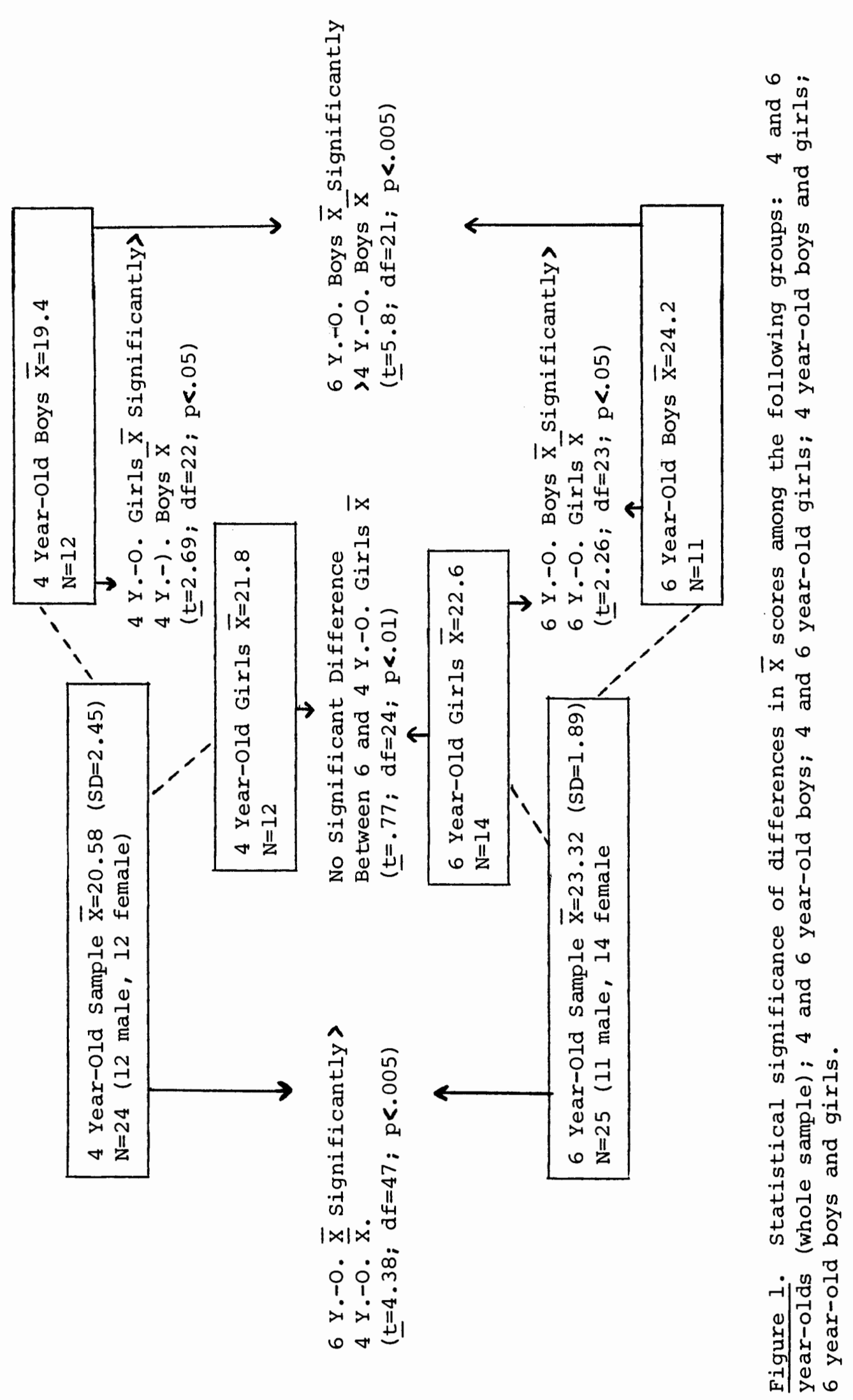


TABLE III

T-TRIP $\overline{\mathrm{X}}$ and S.D.

\begin{tabular}{lcc}
\hline Group & $\overline{\mathrm{x}}$ & $\mathrm{SD}$ \\
\hline $\begin{array}{l}\text { 4 Year-Olds } \\
\text { (Whole Sample) }\end{array}$ & 20.58 & 2.45 \\
$\begin{array}{l}\text { ( Year-Olds } \\
\text { (Whole Sample) }\end{array}$ & 23.32 & 1.89 \\
\hline
\end{tabular}

the boys mean of 24.2 was significantly higher than the girls mean of $22.6(\underline{t}=2.26 ; \mathrm{df}=23 ; \mathrm{p}<.05)$.

The effect of age on T-TRIP scores of boys and girls was measured by applying a two-tailed t-test to the data. Four-year-old boys scored 19.4 which is significantly lower $(\underline{t}=5.8 ; d f=21 ; p .001)$ than the six-year-old boys. The fouryear-old girls mean of 21.8 , however, was not significantly lower $(\underline{t}=.77 ; \mathrm{df}=24 ; \mathrm{p}<.01)$ than the six-year-old mean of 22.6. Comparisons were made to determine if blacks and whites or students at various socioeconomic levels scored differently but no statistically significant differences were found.

\section{Discussion}

The purpose of this study was to gather normative data on T-TRIP scores of normal four and six-year-old children. 


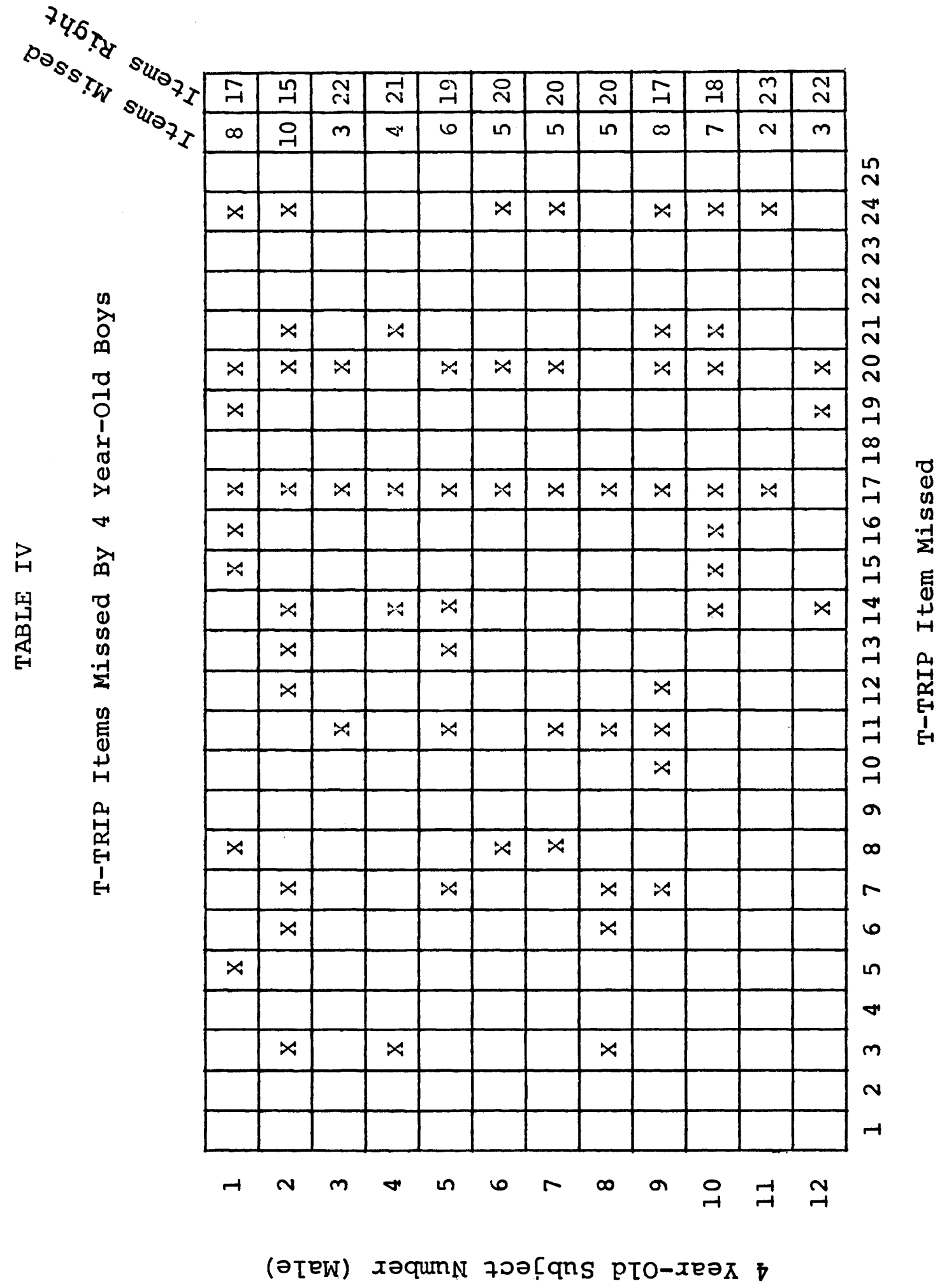




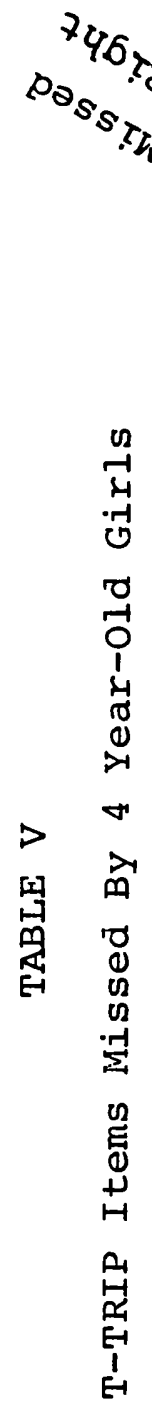

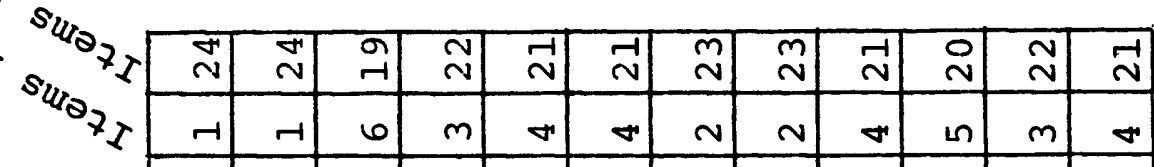

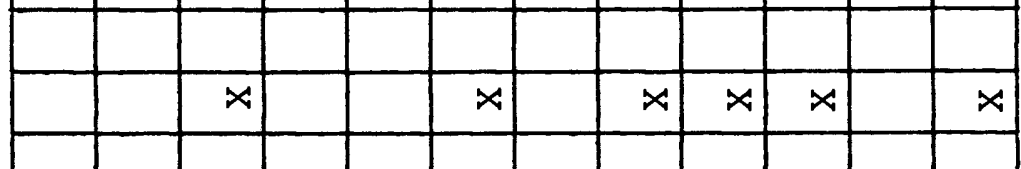

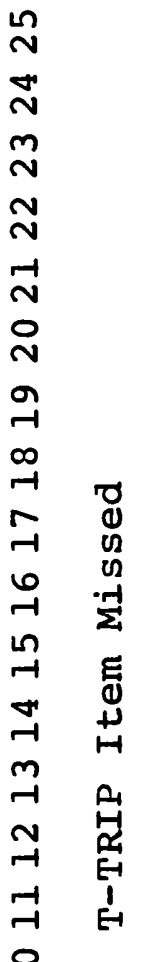

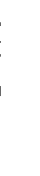
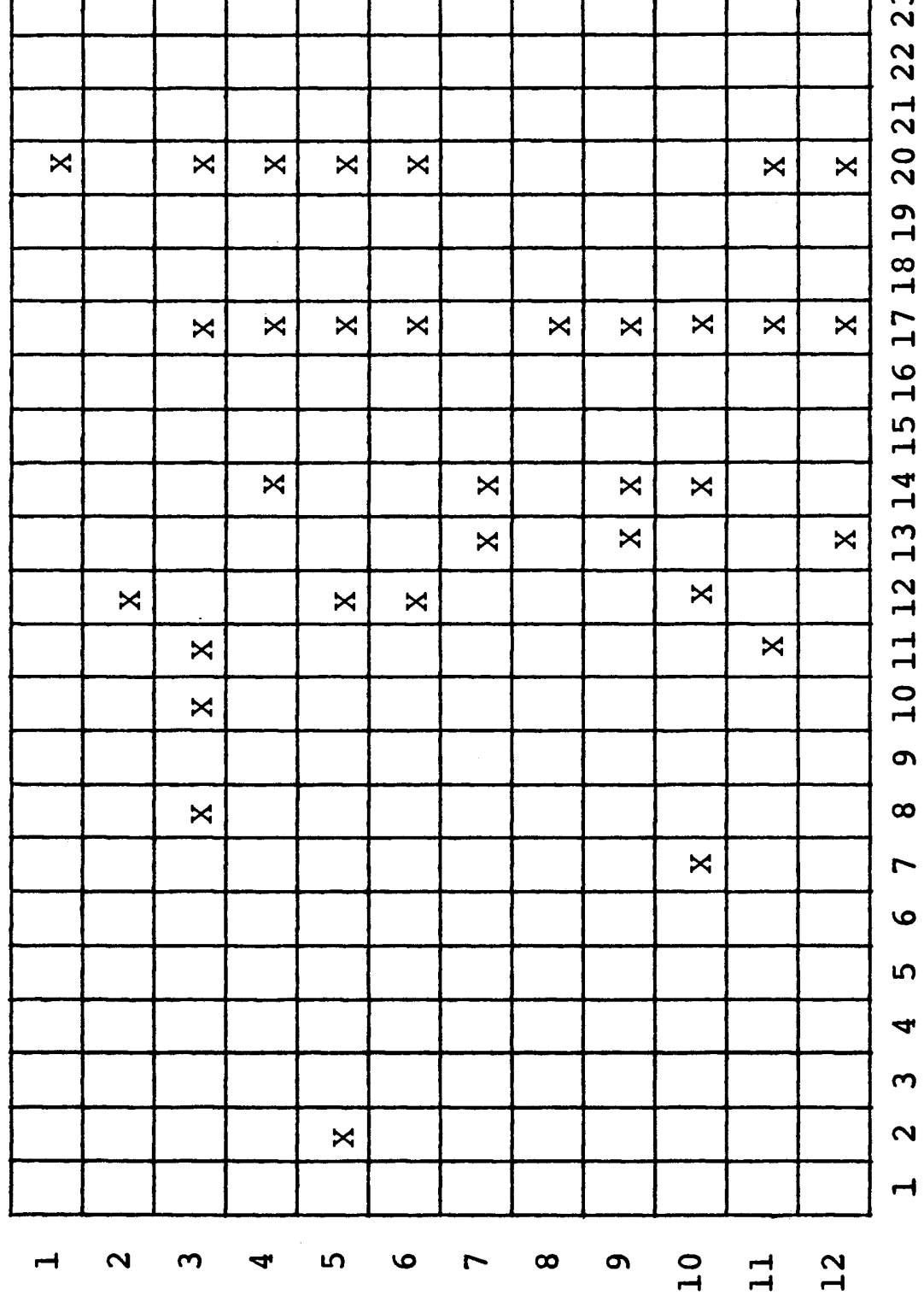

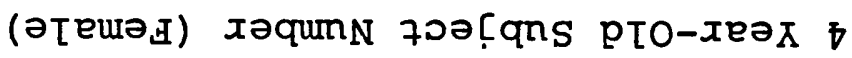




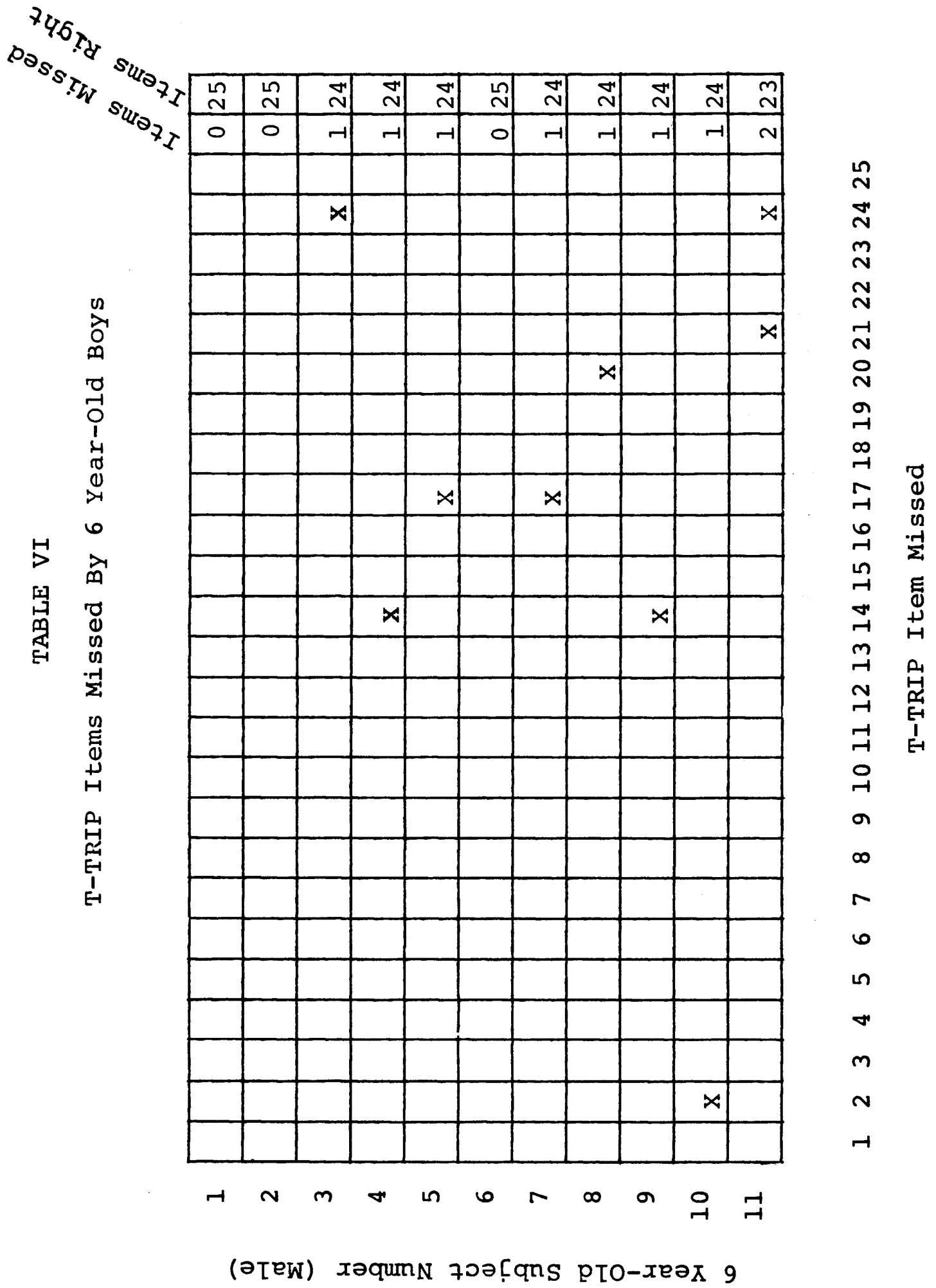




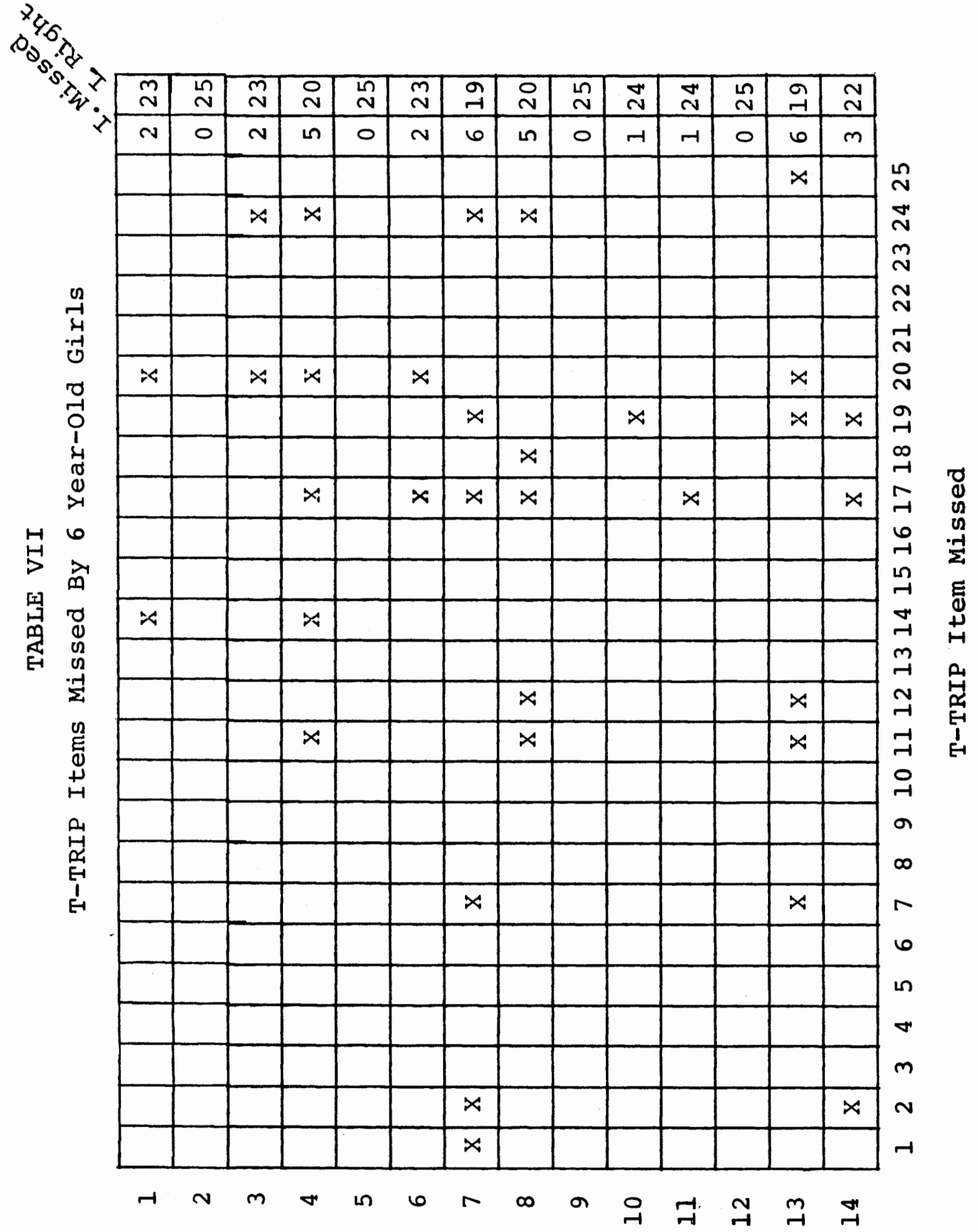

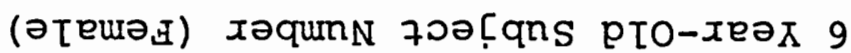


The results show older children generally score higher than do younger children. This is consistent with the findings of the T-TRIP authors, Koike and Asp (1981a). Figure 2 depicts the means and ranges of four and six-year-olds tested for this study and the means and ranges for three and five-yearolds reported by Koike and Asp. These data show a relatively consistent increase in scores as age increases, suggesting the T-TRIP measures skills which improve at a smooth rate between the ages of three and six years. The mean scores in conjunction with standard deviation values give benchmarks for judging how closely a given child's T-TRIP score conforms to scores of other children his age. The means, however, are a somewhat gross measure of ability since they average the results of many different items. A great deal more can be learned about a child's T-TRIP performance by looking at which items he missed. Figure 3 shows the percentage of children in the four age groups who were scored as correct on each test item (the four and six-year-old data are from this study and the three and five-year-old data were reported by Koike and Asp). By comparing a given child's error scores with the values in Figure 3, one may infer whether the child is disordered or delayed on specific skills. A three-yearold, for example, who missed Item 12 should not be considered abnormal since only 30 percent of normal three-year-olds correctly produced the required rhythm and intonation pattern. A six-year-old who missed Item 12 might arouse more concern since only 8 percent of normal six-year-olds missed the item. 


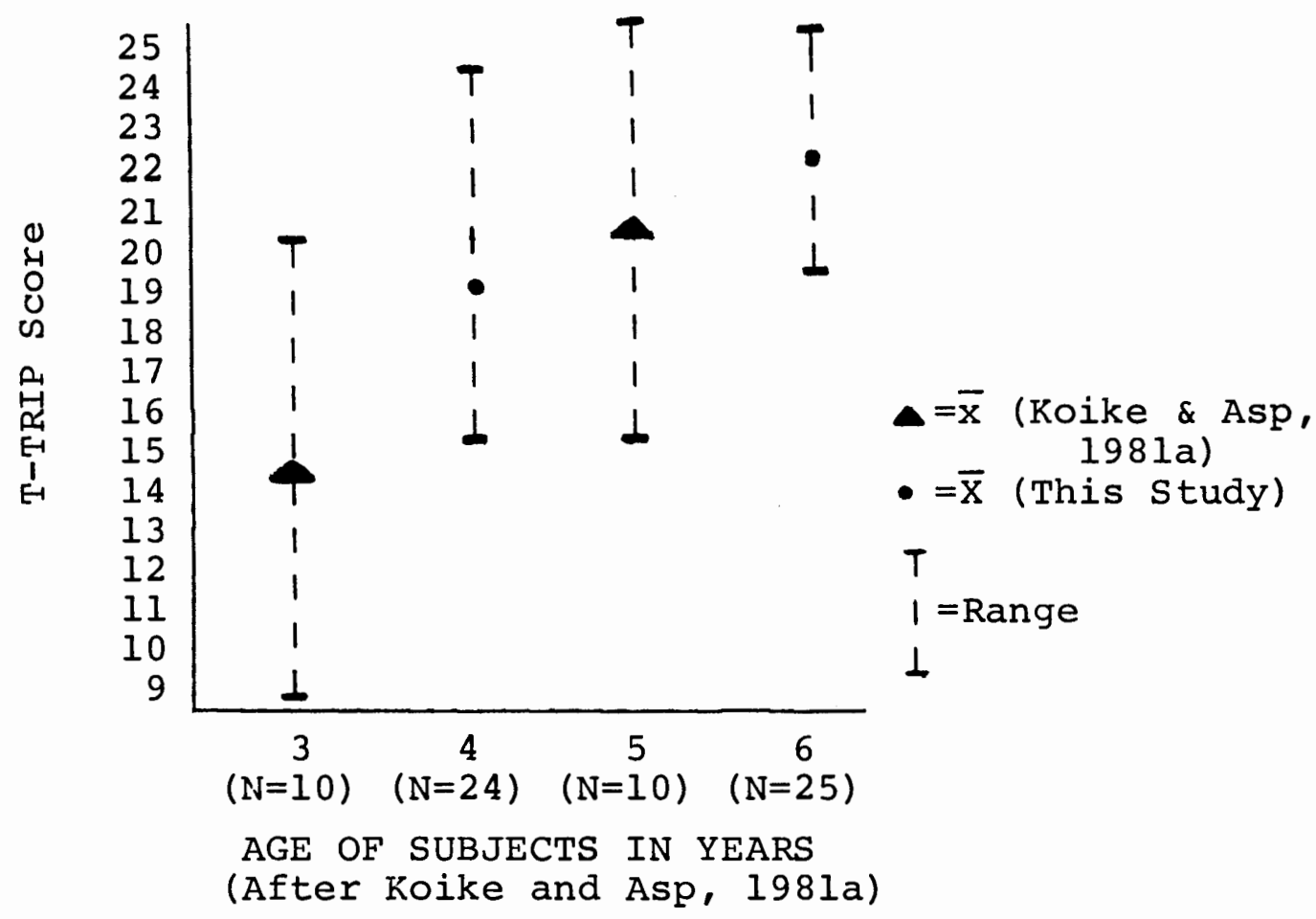

Figure 2. Four and six-year-old T-TRIP scores obtained in this study compared with three and five-year-old T-TRIP scores obtained by Koike and Asp (1981a).

A clinician who uses the information in Figure 3, however, is cautioned that several minor anomalies exist in the data. Three, four and five-year-olds, for example, scored slightly higher on Item 2 than did six-year-olds. It seems unlikely that such an inconsistency truly represents the whole population because that would imply six-year-olds suffer a decrement in abilities they had previously mastered. It is more likely that the small $\mathrm{N}$ in each group allowed one or two poor performers to create an illusory "dip" in scores for a given item. Similar apparent inconsistencies (a younger group scoring higher than an older group) occured on T-TRIP Items $2,3,4,5,11,18,19,22,23,24,25$. Despite the small 


\begin{tabular}{|c|c|c|c|c|}
\hline T-TRIP Item & $\begin{array}{c}3 \text { Year-old } \\
(\mathrm{N}=10)\end{array}$ & $\begin{array}{c}4 \underset{\mathrm{Year}-01 \mathrm{~d}}{(\mathrm{~N}=24)} \\
\mathrm{c}\end{array}$ & 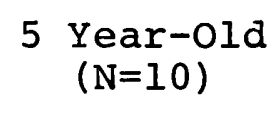 & $6 \begin{array}{c}\text { Year-old } \\
(\mathrm{N}=25)\end{array}$ \\
\hline 1 & 90 & 100 & 90 & 100 \\
\hline 2 & 100 & 96 & 100 & 88 \\
\hline 3 & 70 & 80 & 100 & 96 \\
\hline 4 & 100 & 100 & 90 & 100 \\
\hline 5 & 90 & 96 & 90 & 100 \\
\hline 6 & 70 & 92 & 100 & 100 \\
\hline 7 & 50 & 83 & 90 & 92 \\
\hline 8 & 90 & 80 & 80 & 100 \\
\hline 9 & 90 & 100 & 100 & 100 \\
\hline 10 & 50 & 92 & 100 & 100 \\
\hline 11 & 20 & 70 & 100 & 88 \\
\hline 12 & 30 & 75 & 80 & 92 \\
\hline 13 & 60 & 63 & 100 & 100 \\
\hline 14 & 20 & 63 & 60 & 88 \\
\hline 15 & 70 & 92 & 100 & 100 \\
\hline 16 & 20 & 92 & 100 & 100 \\
\hline 17 & 10 & 17 & 30 & 60 \\
\hline 18 & 90 & 100 & 100 & 96 \\
\hline 19 & 50 & 92 & 100 & 88 \\
\hline 20 & 20 & 37 & 40 & 76 \\
\hline 21 & 60 & 83 & 90 & 92 \\
\hline 22 & 100 & 100 & 90 & 100 \\
\hline 23 & 80 & 100 & 90 & 100 \\
\hline 24 & 20 & 46 & 40 & 76 \\
\hline 25 & 60 & 100 & 100 & 96 \\
\hline
\end{tabular}

Figure 3. The percentage of children who were scored as correct on individual T-TRIP Items: 3 and 5 yearolds (Koike and Asp, 1981a); 4 and 6 year-olds (this study). 
magnitude of the anomalies, clinicians who use an item-byitem analysis of a subject's performance should use the information in Figure 3 as no more than a starting point for further diagnostic procedures.

Figure 3 also gives information about which prosodic skills develop later and earlier in childhood. Items 20 and 24 both entail a falling-to-rising intonation pattern and children of all ages scored relatively poorly on both items. Items 21 and 25, on the other hand, contain all the same prosodic elements but in reverse or rising-to-falling order. The fact that rising-to-falling patterns were imitated correctly more often than falling-to-rising patterns is consistent with Koike and Asp's (1981a) assertion that the former pattern is easier for children to imitate than is the latter. Younger children achieved relatively low scores on Items 13 and 14 which are the only items including pauses. This suggests younger children have difficulty using pauses. The older children, however, scored higher on these items as they apparently gained better control over the ability to use pauses. A factor which may limit younger children's performance on these items is auditory memory. Authorities (e.g., Perkins, 1977) assert auditory memory increases through childhood and this may explain why older children score better than younger children on Items 13 and 14 .

Item 17, which includes a large number of syllables and fast tempo, was the hardest item for children to imitate. With few exceptions, error responses consisted of using too 
few syllables in the second or third set of syllables. This may be the result of a "primacy effect" in which the initial part of a message is properly processed but the middle and final parts are not. Once again, auditory memory may be a factor, i.e., the children simply cannot remember the long string of syllables.

In summary, this study gathered normative data on the T-TRIP scores of normal four and six-year-old children. The data indicate prosodic ability increases fairly steadily between four and six years of age. At four years of age girls scored slightly better than boys, but by the age of six boys scored slightly better than girls. Boys seemed to make more progress in gaining prosodic skills between four and six years of age than did girls but the boys started from a lower proficiency level and therefore had more opportunity to improve. The following elements seemed to make certain T-TRIP items harder than others: falling-to-rising intonation patterns; larger number of syllables; faster tempo; the use of pauses. 


\section{CHAPTER V}

\section{SUMMARY AND IMPLICATION}

\section{Summary}

Prosody is the flow of speech created by controlling elements such as pitch, rate, loudness, and stress (Tiffany and Carrell, 1977). Prosody is vital to intelligibility of speech and also communicates meaning. Despite the importance of prosody, however, few tests for the adequacy of prosodic ability in young children have been published (Koike and Asp, 1981a). To remedy this paucity of tools, Koike and Asp published the Tennessee Test of Rhythm and Intonation Patterns (T-TRIP). The clinical usefulness of the T-TRIP has been limited by a lack of normative data against which to compare individual children's performances.

The purpose of this study was to collect normative data on the T-Trip scores of normal four and six-year-olds. The question this study asked was: What are the means and standard deviations of T-Trip scores from the samples of four and six-year-olds? A secondary question was: Are differences between the means of the two age groups statistically significant?

Twenty-four four-year-olds and twenty-five six-yearolds were selected as subjects on the basis of age, and normalcy of speech, language and hearing development. Each 
subject passed a hearing screening on the day he took the TTRIP .

The mean score for four-year-olds was 20.58 (82 percent) with a standard deviation of 2.45 while the six-year-old mean was 23.32 (93 percent) with a standard deviation of 1.89. A two-tailed t-test revealed the six-year-old mean was significantly greater than the four-year-old mean $(\underline{t}=4.38 ; \mathrm{d} f=47$; $\mathrm{p}<0.05)$.

This study generated information about which T-TRIP items were mastered by which age groups. These data may be useful indicators of the deviance or normalcy of performance in various prosodic skills. Inconsistencies in the data, however, suggest they should be interpreted and applied with due caution in a clinical setting.

\section{$\underline{\text { Research Implications }}$}

If further investigations are undertaken using the TTRIP, several factors should be considered. First, the large inter-subject range of scores in each age group suggests the need for a larger $N$. A large sample would statistically minimize the impact of an exceptionally high or low scoring subject.

Second, a comparison should be made between audio-tape and video-tape presentations of the T-TRIP. The researcher informally probed several subjects and found they performed correctly in response to a live model of items they previously missed. This suggests the added visual information given by 
the clinician model may have helped them perform better. The part played by visual cues in the performance of T-TRIP tasks could be measured by video-taped presentation without sacrificing the stimulus uniformity offered by audio-tape. An associated factor is the acoustical quality of stimulus items. The audio cassette supplied by Koike contained some faint echoes and background noise. The quality of the tape should be improved and perhaps compared with live auditory-only presentation.

Third, the validity of the T-TRIP might be tested by comparing a subject's T-TRIP results with a prosodic analysis of a naturalistic language sample of his speech. Collection of a representative language sample and subsequently analyzing it for prosodic content might present formidable design problems. Such a comparison, nonetheless, would be useful in determining if the T-TRIP accurately measures a subject's prosodic usage in daily speech.

Fourth, the complex interweaving of prosody and pragmatics may be a fruitful area for investigation. A child who displays poor turntaking, for example, might lack sensitivity to prosodic cues with which speakers signal a sentence is complete or still in progress. The T-TRIP could be a usefuI tool in detecting if such a child's pragmatic problems have a prosodic component.

Fifth, non-English speaking children could be tested to see if they perform differently than English speakers on overall score or specific items of the T-TRIP. Deva (1980) 
suggested various languages differ with regard to the importance of prosodic elements such as pitch and duration. A normative study of non-English speakers could help clarify whether their languages entail different prosodic abilities than does English.

Sixth, the T-TRIP may be a valuable tool for use with hearing impaired subjects. A normative study would not only give overall performance scores for this population but would test the assertion (Ling, 1976; Koike and Asp, 1981a) that the hearing impaired have greater trouble mastering certain prosodic elements and patterns. The T-TRIP might also serve as a pre- and post-test of progress in aural rehabilitation work.

Seventh, a different presentation technique and scoring scheme deserves investigation. In this alternative, the stimulus items would be presented on a Language Master. When a subject answered correctly on the first attempt, he would get credit for the item and avoid having to repeat it. When a subject answered correctly on the second attempt, he could still get credit for the item but an added note would indicate he needed two trials. A subject who missed both attempts would not receive credit for the item. This scoring method would yield a percentage score plus a count of "repeats needed" to measure consistency. The main advantage of this alternative scoring and presentation method is a shorter test. The Language Master, by using a separate tape-card for each stimulus item, lends itself to eliminating redundantiterations 
of items the subject already imitated correctly. The imprecise cuing (tape positioning) usually available on cassette recorders makes such skipping of repetitions difficult.

Finally, a system should be devised for recording the type of errors made by subjects. A number of approaches could be taken: (1) a code could be established, e.g., "a" means a pitch error, "b" means an error in the use of pauses, etc.; (2) the clinician could write a verbal description of the erroneous response; (3) a transcript could be made of the erroneous response using the quasi-musical notation shown in the test manual and score sheet.

\section{Clinical Implications}

The normative data generated by this study give benchmarks for T-TRIP performance of normal four and six-year-olds. By comparing a child's score with the norms, a speech-Language Pathologist can determine if a child falls below his age-level peers in prosodic ability. The fact that the T-TRIP yields a score is useful for public school personnel who prepare Individual Education Plans (IEP) which, as mandated by Public Law 94-142, require the results of normed tests to justify special services.

The clinician should be cautious in interpreting T-TRIP scores, however, because the validity of imitative tests in general, and the T-TRIP in specific, has not been persuasively demonstrated. The T-TRIP, therefore, should be augmented by other assessments of a child's prosodic ability. Given 
the dearth of tools available to assess prosody, the clinical user of the T-TRIP is encouraged to employ a keen "clinical ear" in determining which children have prosodic handicaps. 


\section{BIBLIOGRAPHY}

ABE, I. (1980). How vocal pitch works. In I. Waugh and C. van Schoonveldt (Eds.), The melody of language. Baltimore: University Press.

COE, N. (1978). Cross checking aural and oral control. English Language Teaching Journal, 32, 105-107.

CRYSTAL, D. (1969). Prosodic systems and intonation in English. Cambridge: University Press.

CRYSTAL, D. (1973) . Non-segmental phonology in language acquisition: A review of the issues. Lingua, 32, $1-45$.

CRYSTAL, D. (1975). The English tone of voice: Essays in intonation, prosody and paralanguage. London: Arnold.

CRYSTAL, D. and QUIRK, R. (1964). Systems of prosody and paralinguistic features in English. London: Mouton.

DANILOFF, R., SCHUCKERS, G. and FETH, L. (1980). The physiology of speech and hearing. Englewood Cliffs, N.J.: Prentice-Hall, Inc.

DEVA, B. (1980). The vibrato in Indian music. In J. Large (Ed.), Contributions of voice research to singing.

Houston: College Hill Press.

FAIRCLOTH, S. and FAIRCLOTH, M. (1973). Phonetic science: A program of instruction. Englewood Cliffs, N.J.: Prentice-Hall, Inc.

KOIKE, K. (1983). Personal communication.

KOIKE, K. and ASP, C. (1981a). Tennessee test of rhythm and intonation patterns. Journal of Speech and Hearing Disorders, $46,81-87$.

KOIKE, K. and ASP, C. (1981b). The test manual for the Tennessee test of rhythm and intonation patterns. Knoxville, Tenn.: University of Tennessee.

LEHMAN, P. (1968). Tests and measurements in music. Englewood Cliffs, N.J.: Prentice-Hall, Inc.

LENNEBERG, E. (1967) . Biological foundations of language. New York: Wiley. 
LEWIS, M. (1959). How children learn to speak. New York: Basic Books.

LIEBERMAN, M. and STREETER, L. (1978). Use of nonsense-sY1lable mimicry in the study of prosodic phenomena. Journal of the Acoustical Society of America, 63, 231233 .

LIEBERMAN, P. (1967) . Intonation, perception and language. Cambridge, Mass.: MIT Press.

LIEBERMAN, P. (1977). Speech physiology and acoustical phonetics. New York: MacMillan Publishing Co.

LING, D. (1976). Speech and the hearing impaired child: Theory and practice. Washington, D.C.: The Alexander Graham Bell Association for the Deaf, Inc.

MARTIN, J. (1979). Rhythmic and segmental perceptions are not independent. Journal of the Acoustical Society of America, 1287-1312.

MENYUK, P. (1972). The development of speech. New York: Bobbs-Merrill.

NAKATANI, L. and SCHAFFER, J. (1978). Hearing "words" without words: Prosodic cues for speech perception. Journal of the Acoustical Society of America, 63, 234- 245 .

NETSELL, R. (1973). Speech physiology. In F. Minifie, T. Hixson, and F. Williams (Eds.), Normal aspects of speech, hearing and language. Englewood Cliffs, N.J.: Prentice-Hall, Inc.

OLLER, D. (1973). The effect of position in utterance on speech segment duration in English. Journal of the Acoustical Society of America, 54, 1235-2346.

OWENS, E., KESSLER, D., SCHUBERT, E. (1982). Interim assessment of candidates for cochlear implants. Archives of Otolaryngology, 108, 478-483.

PERKINS, W. (1977). Speech pathology an applied behavioral science. St. Louis: C.V. Mosby Co.

PINHEIRO, M. (1976). Auditory pattern perception in patients with left and right hemisphere lesions. Ohio Journal of Speech and Hearing, 12, 9-20.

REESE, T. (1983) . Hearing aid amplification vs. cochlear implants. A paper presented at the 1983 Fall convention of the Oregon and Washington Speech and Hearing Associations, Portland, Oregon. 
SHADDEN, B., ASP. C., TONKOVICH, J. and MASON, D. (1980). Imitation of suprasegmental patterns by five-year-old children with adequate and inadequate articulation. Journal of Speech and Hearing Disorders, 45, 390-400.

TIFFANY, W. and CARRELI, J. (1977). Phonetics theory and practice. New York: McGraw Hill, Inc.

TRAVIS, L. and DAVIS, M. (1927). The relation between faulty speech and lack of certain musical talents. Psychological Abstracts, 36, 71-81.

WEISS, C., LILLYWHITE, H. and GORDON, M. (1980). Clinical management of articulation disorders. St. Louis: C.V. Mosby Company.

WOOD, B. (1981). Children and communication - verbal and nonverbal language development. Englewood Cliffs, N.J .: Prentice-Hall, Inc. 
APPENDIX A

THE TEST MANUAL FOR

THE TENNESSEE TEST OF RHYTHM AND INTONATION PATTERNS

(T-TRIP)

by

Kazunari J.M. Koike, Ph.D.

University of Utah

Division of Speech-Language Pathology and Audiology Salt Lake City, Utah 84112

and

Carl W. Asp, Ph.D.

University of Tennessee

Department of Audiology and Speech Pathology

Knoxville, Tennessee 37916 
PURPOSE

The purpose of the T-TRIP is to measure the number of test items a subject can imitate correctly from a total of 25 test items. Thus, the score can be expressed by a percentage, i.e., a ratio scale.

The T-TRIP has been found to be a reliable measure in various kinds of the population (Koike, 1977; Koike and Asp, 1977; Newsom-Clark, 1977; Tonkovich, et al., 1977; Koike and Asp, 1978; Williams, D., 1978; Williams, V., 1978; Klinedinst, 1979; Shadden, et al., 1980; and Koike and Asp, 1981). However its validity has not yet been fully examined and any statement about a subject's ability to handle "suprasegmentals" should be carefully stated.

TEST

The Tennessee Test of Rhythm and Intonation Patterns (T-TRIP) is constructed with 25 different test items (See Test Form). Symbols are used to identify the rhythm (e.g., stressed to unstressed, and the intonation (e.g., falling intonation, for each test item. Musical notations (See Test Form) are also used so the tester can identify the rhythmical patterns in the appropriate tempo.

The rhythmical patterns have two levels of stress (stressed / $/$ or unstressed / $/ /$ ) and two levels of tempo (regular tempo / $\bullet /$ or quick tempo $/ \because /)$. In a regular tempo, one beat has only one syllable. In a quick tempo, one beat has more than two syllables. Since a stressed syllable is usually accompanied by an increase in pitch (Fairbanks, 1940; and Lehiste, 1970), stressed syllables are given a higher pitch than unstressed syllables (e.g., stressed to unstressed, A pause received one quarter pause (approximately $900 \mathrm{msec}$ ) and is identified by a singla bar / / The intonational patterns have three levels of pitch: (1) low pich--bottom line, (2) mid pitch--middle line, and (3) high pitch --top line. The two types of falling pitch are identified as: gradual falling / $/$ / or fast falling / $/$. Both symbols extend over the three levels of pitch. Only the rate of change is different. The two types of rising pitch are also identified as gradual rising / $-\rightarrow /$ or fast rising / 1 .

The nonsense syllable /ma/ was spoken (repeated) with the appropriate rhythm and intonation patterns and recorded on audio tape according to the test items on the test form. Each syllable is identified by a single dot. The phonemes $/ \mathrm{m} /$ and $/ a /$ were selected because they occur early in the acquisition of articulatory skills (Jakobson, Fant, and Halle, 1972; Menyuk, 1972; and Williams, 1972).

For Part I of the rhythm section, the first 14 test items are systematically varied in tempo and the syllable which receives the stress. For Part II of rhythm (items 15, 16, and 17), the tempo for each beat is increased from one to three syllables to evaluate if young children can imitate a quick tempo. For Part III of intonation (items 18 through 25), each test item has a different intonation pattern; whereas, the rhythm 
pattern changed for every other test item.

METHOD OF PRESENTATION

In presenting the test items, the stimulus tape should preferably be used, even though a trained tester can present the test stimuli in a live voice. The stimulus cassette tape is available from the University of Tennessee, Knoxville.

STOP reading the manual at this point, and please listen to the whole tape.

\section{Instructions for the subjects}

"You are going to hear many different sounds. Listen closely, then repeat exactly what you hear. Are you ready"?

The tester should stop (or pause) the tape recorder after each presentation. Then signal the child to listen for the next presentation.

Practice Items

A subject should be seated facing you. The tape is presented at a most comfortable listening level for each subject. Ask the subject if it is loud enough, but also judge it for yourself. Make sure the subject can hear it.

The first five test items are practice items which consist of Numbers 1, 2, 3, 4, and 13. Each practice item is presented only once. The tester should get the subject familiar to the task. Extra visual and auditory cues such as tapping and hand movements should not be used. However, the subject can be verbally reinforced (e.g., "good," "very good," etc.) periodically by the tester to keep her/him interested in the test, especially for younger children.

The tape should be stopped after each presentation. The pause between each presentation may not be long enough for the subject to respond. So, it is necessary to control the rate of presentation to make it comfortable for the subject. The tester should practice this before testing a subject.

\section{Test Items}

The actual test starts at the sixth test item. Each test item is presented twice, and the subject should respond separately to each presentation. (See Test Form for lst and 2nd presentation for each test item.) Therefore, there are 50 stimulus-response pairs for each subject.

STOP reading again, and listen to the whole tape while looking at the symbols in each test item (See Test Form).

\section{$\underline{\text { Scoring }}$}

The tester scores each response as correct (+) if the subject's response is similar to the stimulus or score it incorrect $(-)$ if it is 
dissimilar to the stimulus or if there is no response (NR) (see the Sample Test Form). The criteria for a correct response is the correct use of number of syllables, stress, pause, tempo, and intonation. The intelligibility of the segmental phonemes should not be used for these judgments. A test item is considered correct if at least one of the two responses is correct. The percent correct for the 25 test items represents the test score on the T-TRIP. this time.

Please listen to the whole tape once again and try to test YOURSELF

If you followed the manual, now you have just listened to the TTRIP three times. The auditory familiarization to the test items is very critical in the T-TRIP, because you will be judging the subject's response against your sense of rhythm and intonation.

Please practice the T-TRIP with a couple of people before you start testing a subject.

Remember, if one of the subject's responses is correct for a test item, the test item is scored as correct. Then, count the number of test items that were correct and compute the percent correct. This is the subject's test score.

In order to get additional response sheets, the tester should have the "blank" response sheet xeroxed. Use these copies for testing the subjects. Then, keep the sample test form only for reference.

DATA

The only request for using the T-TRIP is that we be informed about your test results and any research papers you present or publish. We would also appreciate any comments or suggestions you may have.

The requests for the TEST MANUAL or the research papers related to the T-TRIP should be sent to:

Kazunari J.M. Koike or Carl W. Asp

The University of Tennessee

Department of Audiology and Speech Pathology

Knoxville, Tennessee 37916 
BIBLIOGRAPHY

Fairbanks, G., Voice and Articulation Drillbook. Evanston: Harper \& Row, 1940.

Jakobson, R., Fant, G., and Halle, M., Preliminaries to Speech Analysis, The Distinctive Features and Their Correlates. Cambridge: M.I.T. Press, 1972 .

Koike, K., A test of rhythm and intonation patterns for young normalhearing children. Unpublished Master's Thesis, The University of Tennessee, Knoxville, Tennessee, 1977.

Koike, K., and Asp, C.W., A test of rhythm and intonation patterns: a pilot study. J. Acoust. Soc. Am. $62(1): 547$ (a), 1977.

Koike, K., and Asp, C.W., The Tennessee test of rhythm and intonation patterns (T-TRIP). A paper presented at the American speech and Hearing Association convention in San Francisco, 1978.

Klinedinst, S., The relationship of suprasegmentals language and musical abilities. Unpublished Master's Thesis, The University of Tennessee, Knoxville, Tennessee, 1979.

Lehiste, I., Suprasegmentals. Cambridge: M.I.T. Press, 1970 .

Menyuk, P., The Development of Speech. New York: Bobbs-Merrill, 1972.

Newsom-Clark, S., and Asp, C.W., Imitation of suprasegemental patterns by 40,50 , and 60 year old adults with normal hearing. Unpublished study, The University of Tennessee, 1977.

Shadden, B., Asp, C.W., Tonkovich, J., and Mason, D., Imitation of suprasegmental patterns by five-year old children with adequate and inadequate articulation. J. Speech Hearing Dis., 45, 390-400, 1980.

Tonkovich, J., Asp, C., Shadden, B., and Mason, D., Imitation of suprasegmental patterns by apraxic and normal adult speakers. Unpublished study, Department of Audiology and Speech Pathology, Knoxville, Tennessee, 1978.

Williams, D., Suprasegmental patterns and word intelligibility of hearingimpaired children trained with the Verbo-tonal Method. Unpublished Master's Thesis, The University of Tennessee, Knoxville, Tennessee, 1978. 
Williams, F., Language and Speech, Introductory Perspectives. Englewood Cliffs: Prentice-Hall, 1972.

Williams, V.L., Suprasegemental skills, segmental skills, and word intelligibility of hearing impaired and normal hearing children. Unpublished Master's Thesis, The University of Tennessee, Knoxville, Tennessee, 1978 . 


\section{APPENDIX B}

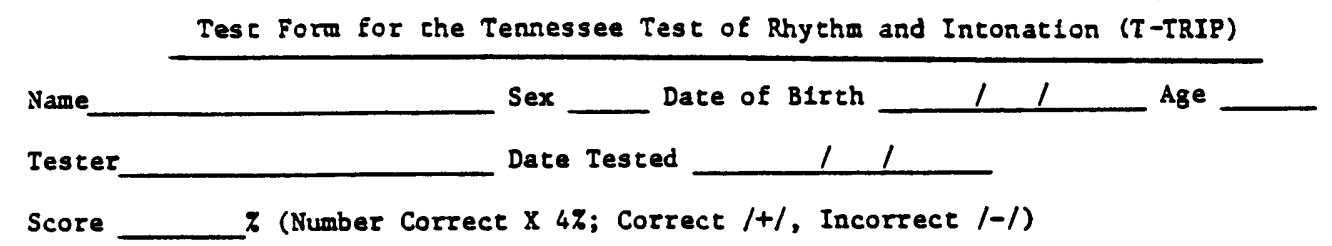

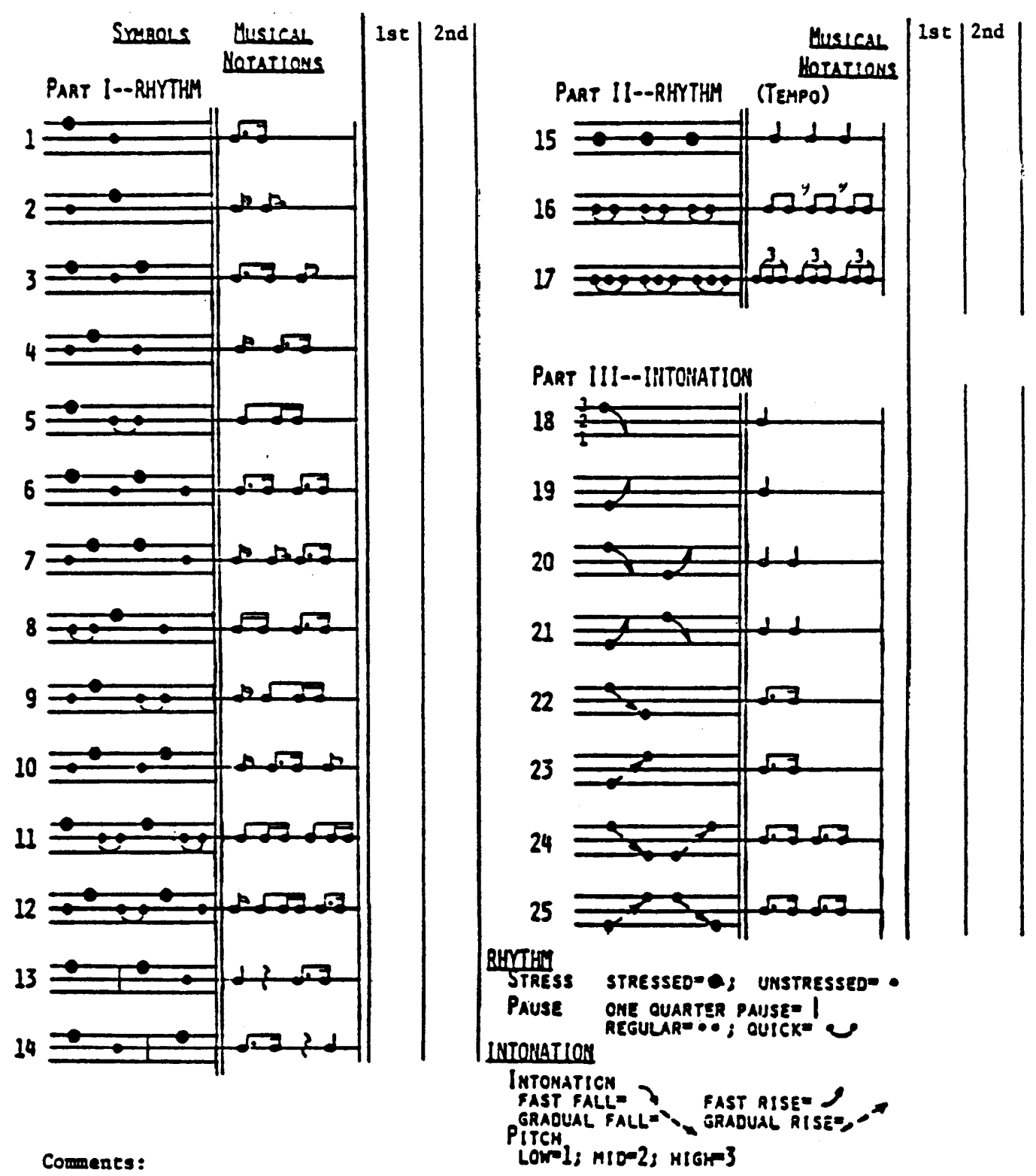

